University of Nebraska - Lincoln

DigitalCommons@University of Nebraska - Lincoln

$4-2-2006$

\title{
Spectral Network (SpecNet)-What is it and why do we need it?
}

John A. Gamon

California State University, jgamon@gmail.com

A. F. Rahman

Texas Tech University

J. L. Dungan

NASA Ames Research Center

M. Schildhauer

National Center for Ecological Analysis and Synthesis

K. F. Huemmrich

University of Maryland - Baltimore County

Follow this and additional works at: https://digitalcommons.unl.edu/nasapub

Part of the Physical Sciences and Mathematics Commons

Gamon, John A.; Rahman, A. F.; Dungan, J. L.; Schildhauer, M.; and Huemmrich, K. F., "Spectral Network (SpecNet)-What is it and why do we need it?" (2006). NASA Publications. 7.

https://digitalcommons.unl.edu/nasapub/7

This Article is brought to you for free and open access by the National Aeronautics and Space Administration at DigitalCommons@University of Nebraska - Lincoln. It has been accepted for inclusion in NASA Publications by an authorized administrator of DigitalCommons@University of Nebraska - Lincoln. 


\title{
Spectral Network (SpecNet) - What is it and why do we need it?
}

\author{
J.A. Gamon $^{\text {a,* }}{ }^{\text {, A.F. Rahman }}{ }^{\text {b }}$, J.L. Dungan ${ }^{\text {c }}$, M. Schildhauer ${ }^{\text {d }}$, K.F. Huemmrich ${ }^{\text {e }}$ \\ ${ }^{a}$ Department of Biological Sciences, California State University, Los Angeles, 5151 State University Drive, Los Angeles, CA 90032, USA \\ b MS2125, Texas Tech University, Lubbock, TX 79409, USA \\ ${ }^{\mathrm{c}}$ MS 242-4, NASA Ames Research Center, Moffett Field, CA 94035-1000, USA \\ ${ }^{\mathrm{d}}$ National Center for Ecological Analysis and Synthesis, 735 State St., Suite 300, Santa Barbara, CA 93101-3351, USA \\ e Joint Center for Earth Systems Technology (JCET), University of Maryland, Baltimore County, Code 614.4, NASA/GSFC, Greenbelt, MD 20771, USA
}

Received 17 March 2006; received in revised form 1 April 2006; accepted 2 April 2006

\begin{abstract}
Effective integration of optical remote sensing with flux measurements across multiple scales is essential for understanding global patterns of surface-atmosphere fluxes of carbon and water vapor. SpecNet (Spectral Network) is an international network of cooperating investigators and sites linking optical measurements with flux sampling for the purpose of improving our understanding of the controls on these fluxes. An additional goal is to characterize disturbance impacts on surface-atmosphere fluxes. To reach these goals, key SpecNet objectives include the exploration of scaling issues, development of novel sampling tools, standardization and intercomparison of sampling methods, development of models and statistical methods that relate optical sampling to fluxes, exploration of component fluxes, validation of satellite products, and development of an informatics approach that integrates disparate data sources across scales. Examples of these themes are summarized in this review.
\end{abstract}

(C) 2006 Elsevier Inc. All rights reserved.

Keywords: SpecNet (Spectral Network); Optical remote sensing; Surface-atmosphere flux; Scaling; Satellite validation; FLUXNET

\section{Introduction}

One of the pressing scientific challenges of our time is to better quantify the exchanges of gases between the biosphere and the atmosphere. Of prime importance are the fluxes of carbon and water through the processes of photosynthesis, respiration, and evapotranspiration. This essential "breathing" of the planet provides a fundamental indicator of the biosphere's metabolism and is critical to the regulation of the atmosphere and climate. This gas exchange is extremely variable with both short- and long-term perturbations, and is affected by ongoing changes in atmospheric gas composition and climate. If we are to fully understand the processes controlling the exchanges of carbon, water, and energy at the Earth's surface, and the implications of these fluxes for climate and global biogeochemical cycles, then we must be able to quantify these dynamic fluxes. Because of its synoptic sampling capabilities,

\footnotetext{
* Corresponding author.

E-mail address: jgamon@gmail.com (J.A. Gamon).
}

remote sensing plays a key role in monitoring biosphereatmosphere fluxes.

A number of factors conspire to make the quantification of these fluxes, and the understanding of their underlying controls, a difficult challenge. Surface-atmosphere gas fluxes are inherently dynamic, varying dramatically over hours, days or weeks as environmental conditions change. Simple changes in cloud cover, temperature or moisture status can exert profound effects on surface-atmosphere fluxes, with further feedback to the climate system (Goulden et al., 1997; Sellers et al., 1996). A variety of disturbances to the Earth's atmosphere, climate and biogeochemical cycles, both anthropogenic and natural, lead to additional dynamics in these fluxes. Further challenges in quantifying these fluxes arise from the fundamental mismatch in scale between flux sampling and remote sensing measurements (Raupach et al., 2005), a key SpecNet topic considered in more detail below. Additionally, the controls of ecosystematmosphere gas fluxes may operate at different spatial and temporal scales from those of our measurements. To address these challenges, we need sampling and modeling approaches 

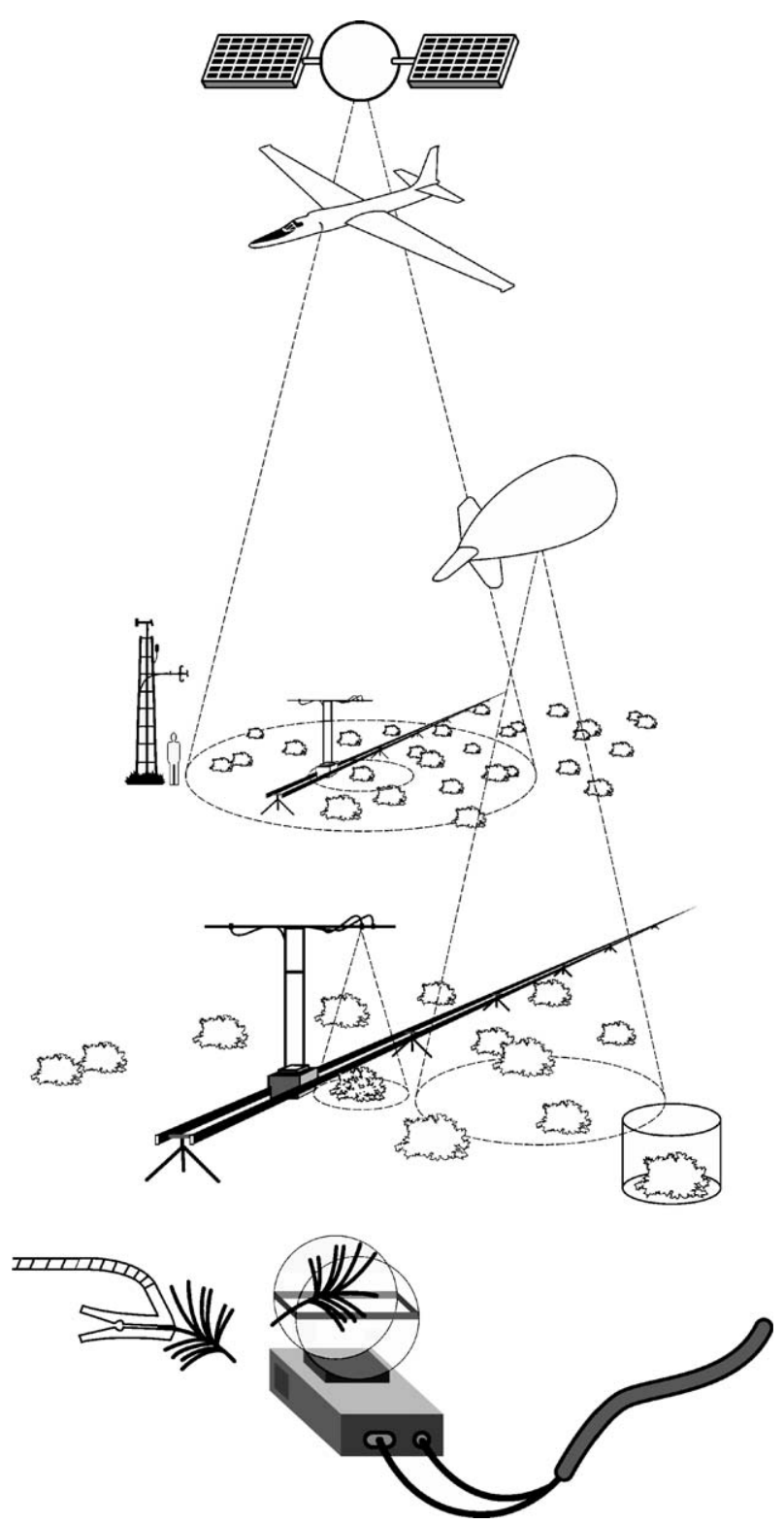

Fig. 1. Multiscale optical sampling as applied at SpecNet sites. Sampling methods range from satellites, aircraft, low-altitude airborne platforms, mobile tram systems, and portable spectrometers. Certain sampling methods (e.g. portable spectrometers, mobile tram systems, and low-altitude airborne platforms) sample at spatial scales that can be directly related to gas fluxes (sampled via gas exchange chambers or eddy covariance towers). Repeated optical sampling (possible with certain optical methods such as the tram) facilitates comparison with temporal dynamics in gas fluxes. Comparison of optical sampling across multiple scales allows cross-scale analyses, including validation of satellite remote sensing. Figure adapted from Estrin et al., 2003.

that directly address the scale mismatch between remote sensing and flux measurements and that explicitly consider the scales most relevant to the controls of ecosystem fluxes.

The Spectral Network (SpecNet, http://specnet.info) is designed to address these needs by applying scale-appropriate optical sampling in conjunction with flux measurements. SpecNet is a collaborative network and data sharing cooperative that integrates optical sampling with ecosystem-atmosphere fluxes of biologically and radiatively important gases, including carbon dioxide and water vapor. In this context, "optical sampling" refers to remote sensing, typically reflectance measurements in the visible, NIR and SWIR wavelengths (roughly 400-2500 nm). Other methods (e.g. fluorescence, thermal emission, and active remote sensing methods) are also considered. Reflectance sampling can be conducted at a range of scales, including individual leaves using portable or laboratory spectrometers, whole canopies or stands using mobile field sampling and low-altitude platforms, and large landscapes using satellite imaging spectrometers (Fig. 1). One of the benefits of optical sampling is that, unlike many other sampling methods (gas exchange, for instance), it can readily be applied across a wide range of spatial scales, making it an excellent scaling tool. The need to address sampling at multiple scales in both temporal and spatial dimensions (see Table 1) is leading to many new innovations in instrumentation, sampling platforms, methodology, data management and interpretation, some of which are considered in this special issue.

SpecNet originated as a Working Group that met at the National Center for Ecological Analysis and Synthesis in 2003 and is envisioned as a global network for optical sampling and remote sensing concurrent with measurements of carbon, energy, and water flux. Since its inception, SpecNet has grown to include over 20 sites around the world, covering a wide range of ecosystem types (See Table 2). A primary SpecNet focus is on existing sites within the FLUXNET network, where eddy covariance measurements are in place, although sites with other flux measurements (e.g. ecosystem chamber fluxes) are also considered.

Specific goals of SpecNet include: 1) understanding the controls on surface-atmosphere fluxes of carbon and water vapor, and 2) understanding the impacts of disturbance (e.g. land-use change, fire, extreme weather events, and climate change) and other dynamic events on surface-atmosphere fluxes. Flux controls can include the biotic or abiotic factors affecting component fluxes, including photosynthetic and respiratory fluxes, or transpiration from vegetation versus evaporation from soil. Alternatively, they can include the contribution of different species, functional types, cover types, or landscape units to overall ecosystem fluxes. Since disturbance can alter these controls and affect the partitioning between these components, a key goal is to investigate disturbance impacts and flux dynamics by means of linked optical and flux measurements.

Table 1

The concept of "scale" as it relates to SpecNet includes spatial, temporal and spectral dimensions, and their corresponding sampling units and extents, as described below

\begin{tabular}{lll}
\hline Dimension & Sampling unit & Extent \\
\hline Spatial & $\begin{array}{l}\text { Grain size, pixel size or } \\
\text { field-of-view }\end{array}$ & $\begin{array}{l}\text { Extent of region covered } \\
\text { by a sample }\end{array}$ \\
Temporal & $\begin{array}{l}\text { Time interval for a } \\
\text { single measurement }\end{array}$ & $\begin{array}{l}\text { Elapsed time from beginning } \\
\text { to end of sampling }\end{array}$ \\
Spectral & $\begin{array}{l}\text { Spectral bandpass } \\
\text { (bandwidth) }\end{array}$ & Spectral range \\
& & \\
\hline
\end{tabular}


Table 2

Examples of existing SpecNet sites, listing ecosystem type, participating investigators, and the approximate starting date of systematic optical sampling (source: http:// specnet.info)

\begin{tabular}{|c|c|c|c|c|}
\hline Country & Site name & Ecosystem type & Investigator(s) & Starting date \\
\hline Australia & Tumburumba & $\begin{array}{l}\text { Wet sclerophyll } \\
\text { Eucalyptus forest }\end{array}$ & R. Leuning & June 2002 \\
\hline Canada & Campbell River & Douglas-fir forest & N. Coops, A. Black & Jan 2006 \\
\hline Costa Rica & Los Inocentes & Tropical moist forest & A. Sanchez-Azofeifa, J. Calvo & Jan 2002 \\
\hline Costa Rica & Santa Rosa and Palo Verde & Tropical dry forest & A. Sanchez-Azofeifa, J. Calvo & Jan 2002 \\
\hline Italy & Monte Bondone & Alpine grassland & D. Gianelle, L. Vescovo & May 2005 \\
\hline Japan & Naeba Mountains & Beech forest & Y. Kakubari, A. Sanchez-Azofeifa & Apr 2003 \\
\hline Mexico & Chamela & Tropical dry forest & A. Sanchez-Azofeifa and M. Quesada & Sep 2003 \\
\hline Mexico & La Paz & Sonoran desert & S. Hastings, C. Salinas, W. Oechel & Jul 2002 \\
\hline Sweden & Stordalen & Subarctic mixed mire & $\begin{array}{l}\text { T.R. Christensen, T. Friborg, } \\
\text { P. Crill, T. Johansson }\end{array}$ & Jun 2002 \\
\hline UK & Harwood Forest & Sitka spruce & C. Nichol, J. Grace & Jul 2003 \\
\hline USA & Alaska — Atqasuk/Barrow & Arctic tundra & $\begin{array}{l}\text { J. Gamon, F. Huemmrich, } \\
\text { W.Oechel, H. Kwon, Y. Harazono }\end{array}$ & Jun 2000 \\
\hline USA & Arizona - Charleston Mesquite & Mesquite woodland & R. Scott, T. Huxman, D. Williams & 2001 \\
\hline USA & Arizona - Lewis Springs Mesquite & Mesquite shrubland & T. Huxman, R. Scott, D. Williams & Mid-2002 \\
\hline USA & Arizona - Lewis Springs Sacaton & Sacaton grassland & T. Huxman, R. Scott, D. Williams & Mid-2002 \\
\hline USA & Arizona — Santa Rita Mesquite & Upland mesquite & R. Scott, T. Huxman, D. Williams & 2004 \\
\hline USA & California — Sky Oaks & Chaparral & J. Gamon, W. Oechel, D. Sims & Jun 2000 \\
\hline USA & California - Cheeseboro Canyon & Annual grassland & J. Gamon, Y. Cheng & Dec 2002 \\
\hline USA & California — Ione & $\begin{array}{l}\text { Annual grassland } \\
\text { and oak grass savanna }\end{array}$ & D. Baldocchi & Oct 2000 \\
\hline USA & California - San Joaquin Marsh & Marshland & M. Goulden, J. Gamon, Y. Cheng & July 2003 \\
\hline USA & California - Santa Margarita & Coastal sage scrub & J. Gamon & Apr 2002 \\
\hline USA & Indiana - Morgan Monroe State Forest & Deciduous forest & H. Peter-Schmid, A. Oliphant, F. Rahman, & Apr 2002 \\
\hline USA & Nebraska - Mead & Agro-ecosystem & $\begin{array}{l}\text { A. Gitelson, D. Rundquist, S. Verma, } \\
\text { T. Arkebauer, E. Walter-Shea }\end{array}$ & Jun 2001 \\
\hline USA & Nevada — Nevada Test Site & Mojave desert & $\begin{array}{l}\text { T. Huxman, S. Smith, L. Fenstermaker, } \\
\text { J. Gamon }\end{array}$ & Apr 2002 \\
\hline USA & $\begin{array}{l}\text { New Hampshire - Bartlett } \\
\text { Experimental Forest }\end{array}$ & Northern hardwoods & $\begin{array}{l}\text { A. Richardson, D. Hollinger, } \\
\text { M.L. Smith, S. Ollinger }\end{array}$ & May 2004 \\
\hline USA & North Carolina - Duke Forest & Hardwood and pine & G. Katul, D. Ellsworth, F. Rahman, S. Ollinger & Jun 2002 \\
\hline
\end{tabular}

To attain these larger goals, SpecNet has several specific objectives, including:

1) addressing issues of sampling scale,

2) developing and testing novel optical sampling methods and platforms,

3) comparing and standardizing optical sampling methods,

4) relating optical signals to fluxes through models and statistical approaches,

5) exploring spatial and temporal patterns of landscape fluxes,

6) developing optical methods to explore component fluxes,

7) evaluating satellite products (flux estimates or products used to derive these estimates), and

8) addressing the informatics challenge of linking optical to flux measurements.

These goals and objectives are discussed in more detail below.

\section{Goals and objectives}

\subsection{Sampling scale}

A key challenge in quantifying surface-atmosphere fluxes over large regions arises from the fundamental scale mismatch between flux and remote sensing measurements (Raupach et al., 2005). In this context, "scale" refers to both sampling unit size and extent, and involves spatial, temporal, and spectral dimensions (see Table 1). While we have excellent tools for estimating gas fluxes of individual leaves, soil patches, and representative samples of certain ecosystems, and we have atmospheric sampling methods (Tans et al., 1990) and satellite systems (e.g. MODIS on the Aqua and Terra platformsRunning et al., 1999) for synoptic measurements of large regions of the Earth, we have considerable challenges in understanding how the parts sum up to the whole. These challenges have a variety of causes, but fundamental among them is the fact that most flux measurements measure a single point or small region ('footprint') through time, while remote sensing often covers very large regions with poor resolution of fine spatial patterns or temporal processes. Additionally, most flux methods (e.g. eddy covariance) sample net ecosystem fluxes, whereas optical sampling is more closely linked to component fluxes (e.g. gross photosynthesis and respiration of actively growing vegetation). This sampling mismatch between flux and remote sensing measurements make it difficult to directly relate the two types of measurement, and often requires the use of statistical approaches or models to integrate fluxes with optical sampling. Newer satellite systems with frequent global 
coverage (e.g. MODIS) are partly addressing the temporal sampling need, but at very coarse spatial resolution that cannot easily be compared to single-point measurements of surface fluxes.

Thus, a key theme of SpecNet is the concept of scaleappropriate optical sampling, and several papers in this issue address this theme. Here, we mean sampling that explicitly considers the operating scale of flux controls and measurements (e.g. the dynamic footprint of the eddy covariance tower), something that is difficult to do with coarse-resolution satellite sampling. This requires explicit consideration of sampling units and extents within time and space (Table 1), providing a solid foundation for extrapolating to larger scales (see Sections 2.4 and 2.5 below). Recent studies integrating remote sensing with fluxes are starting to address the temporal scaling challenges (Sims et al., 2005) but much work remains to be done to develop operational approaches to temporal and spatial scaling. Additionally, the optical sensor must have a spectral resolution and range appropriate to the task at hand - something that is only beginning to be defined, but is a primary concern of SpecNet.

\subsection{Novel sampling methods and platforms}

Several papers in this issue discuss novel sampling methods and platforms addressing the need for scale-appropriate optical sampling. Leuning et al. (2006-this issue) present a multi-angle spectrometer for automatic sampling of plant canopy reflectance spectra from eddy covariance (flux) towers. Results of this continuous, automated sampling approach, and the challenges of relating field data to periodic satellite overpasses, are further discussed by Hill et al. (this issue). Similarly, Gamon et al. (2006-this issue) present a novel dual-detector system mounted on a "tram system" for automated, mobile sampling of surface reflectance in the vicinity of a flux tower. The results from this tram, and comparisons with other, independent sampling approaches, are further discussed in several other studies (Chen \& Vierling, 2006-this issue; Claudio et al., 2006-this issue; Fuentes et al., 2006-this issue; Sims et al., 2006-this issue). Finally, Vierling et al. (2006-this issue) demonstrate a blimp-mounted application of remote photography and spectrometry (The Short Wave AerostatMounted Imager, SWAMI).

These novel instruments and platforms provide examples of "mid-range" remote sensing at resolutions intermediate between those of a typical hand-held spectrometer and a satellite sensor (Fig. 1). The benefit of this mid-range sampling is that it more closely matches the spatial (and possibly temporal) scales of flux tower sampling, providing comparisons between optical signals and surface-atmosphere fluxes and facilitating evaluation of satellite signals. Such independent validation is essential if we are to draw quantitative conclusions from satellite data. Such scale-appropriate intermediate-range optical sampling is often missing from remote sensing campaigns, yet can clearly play an important supporting role in such campaigns (Gamon et al., 2004) and is a main focus of SpecNet.

\subsection{Intercomparison and standarization}

One of the primary challenges of interpreting optical measurements lies in the diversity of sampling instruments, methods, and scales (Fig. 1), leading to the need to standardize our methods for intercomparison. This challenge is evident at the leaf level, where a diversity of sampling instruments and protocols exist (e.g. Daughtry et al., 1989; Dawson et al., 1998; Gamon \& Surfus, 1999). Since many of these methods involve removing the foliage for laboratory analysis, Foley et al. (2006this issue) explored the effect of removal on leaf reflectance, and demonstrate that dehydration was a primary concern, leading to artifacts mainly in the NIR and SWIR regions (where water absorption bands are most evident). Castro-Esau et al. (2006-this issue) compared different methods and instruments for measuring leaf reflectance, revealing significant differences in spectral reflectance and in reflectance indices attributable to both instrument and sampling method, with some reflectance wavelengths and indices varying more than others. The recommendations from these leaf-level studies should be of interest to those exploring leaf reflectance properties, which are often used to infer biochemical content and physiological state (e.g. Gamon \& Surfus, 1999), or to provide fundamental inputs for radiative transfer models (eg. Goel, 1988; Verhoef, 1984).

At a larger scale, Fuentes et al. (2006-this issue), conducted a multi-resolution comparison of indices across remote sensing platforms (AVIRIS vs. field spectrometry from a tram) and found significant differences between sensors for certain indices (PRI and WBI) but not others (NDVI), again revealing spectral regions and reflectance indices that are particularly sensitive to instrument differences. These differences in sensor products have large implications for any cross-site comparisons and are further discussed below in the context of satellite validation (see Section 2.7).

\subsection{Relating optical signals to fluxes}

The explicit comparison of reflectance indices and measurements of carbon and water vapor fluxes, with attention to matching spatial and temporal scales, is a central objective of SpecNet, and several papers address this need. Using a hyperspectral sensor mounted on a mobile "tram system," Claudio et al. (2006-this issue) explored the Water Band Index (WBI), derived from the $970 \mathrm{~nm}$ water absorption feature in reflectance spectra as an indicator of evapotranspiration. Their promising results illustrate the potential to develop flux models from water absorption features present in reflectance spectra. This approach is further developed in Fuentes et al. (2006-this issue) who demonstrated that the Water Band Index (WBI) derived from airborne imaging spectrometry can be used to generate empirical maps of evapotranspiration. This illustrates that one of the primary benefits of adding calibrated optical remote sensing to flux tower sites is its ability to derive explicit "physiological maps" illustrating spatial patterns of fluxes invisible to the flux tower. Given the fact that eddy covariance measurements have fundamental limitations due to their requirements of 
relatively level terrain and homogenous landscapes (Moncreiff et al., 1996), remote sensing can play a critical role in extrapolating flux estimates to larger, non-ideal regions that cannot be directly sampled, which make up most of the Earth's terrestrial surface. Clearly, proper linkage of scaleappropriate optical sampling to flux measurements, now provided by several SpecNet sites, is an essential foundation for this spatial extrapolation.

Sims et al. (2006-this issue) compared several years of leaf and tram reflectance data to carbon flux from an eddy covariance tower for a chaparral ecosystem, leading to several notable findings. One is that NDVI from a nadir sampling view fails to capture the seasonal and year-to-year variability in carbon flux, which agrees with previous reports from this and other similar ecosystems (Gamon et al., 1995; Stylinski et al., 2002). However, a simple empirical correction for sun angle (made possible by the diurnal reflectance sampling capability of the tram) accounts for interactions between sun angle and canopy structure, yielding a "sun-angle corrected" NDVI that is remarkably well-correlated with the carbon flux from this ecosystem. The importance of explicitly considering sun angle and stand structure is often mentioned in the context of BRDF studies (e.g. Asner et al., 1998; Middleton, 1992) and the development of a novel, yet simple, empirical approach to this issue offers a way to improve estimates of carbon flux based on remote sensing.

Sims et al. (2006-this issue) also took a critical look at the Photochemical Reflectance Index (PRI), an index originally intended for detection of diurnal xanthophyll cycle activity (Gamon et al., 1992), and sometimes applied as an index of ecosystem photosynthetic light-use efficiency over longer time spans (Nichol et al., 2000; Rahman et al., 2004). In the critical analysis by Sims et al. (2006-this issue), PRI worked relatively well as a photosynthetic index during periods of "normal" rainfall, but poorly during periods of severe drought, which were marked by leaf loss and canopy senescence, a finding that echoes similar results in other drought-prone systems where canopies undergo large structural changes (Filella et al., 2004; Gamon et al., 1992). Again, this confounding effect of severe drought on PRI highlights the need for much more careful consideration of the effects of ecosystem perturbations and changing stand structure on reflectance indices. It also provides a cautionary tale for current efforts to estimate carbon flux using light-use efficiency models from simple reflectance indices alone (e.g. Rahman et al., 2001, 2004), without further consideration of different ecosystem responses to prevailing environmental conditions.

A conclusion from these studies is that surface-atmosphere flux models derived from remote sensing should be informed by further ecological or structural information about the ecosystem in question and should be validated against actual optical and flux data collected independently across a range of biome types. The varying efficacy of these reflectance indices due to variable sun angle, stand structure, and environmental conditions within a single ecosystem (Sims et al., 2006-this issue) poses serious questions about the validity of our current approaches to global carbon cycle modeling using reflectance indices and suggest that further refinement of these approaches could yield additional model improvements. Clearly, global carbon cycle modeling would benefit from empirical validation and calibration from a network of sites across contrasting ecosystems, a specific SpecNet objective. Such validation deserves much further attention if we are to attain defensible surfaceatmosphere flux measurements (Turner et al., 2003, 2005).

Because the integration of optical and flux measurements is directly under its purview, SpecNet makes an ideal testbed for the development and application of carbon and water-vapor flux models, particularly those models driven by remote sensing. In part for this reason, SpecNet encourages a quantitative and experimental (i.e. comparative) approach to sampling, one that can provide error estimates and direct conclusion of "what works best," - all essential but often neglected aspects of model development and remote sensing. As novel sensors and measurement methods are developed, attention must be placed on directly characterizing uncertainty that comes from a variety of sources (e.g. misregistration of optical and flux measurements, sensor noise, calibration and preprocessing errors) if true quantitative comparison and validation are to be achieved.

\subsection{Exploring spatial and temporal patterns}

The issue of spatial variability in surface properties across landscapes, and within flux tower footprints in particular, is a key issue being explored by the SpecNet community, particularly since flux measurements alone cannot resolve these spatial patterns. Oliphant et al. (2006-this issue) used IKONOS images in a detailed exploration of the spatial patterns of absorbed photosynthetically active radiation (APAR, a critical term within ecosystem carbon uptake models) for a deciduous forest within the vicinity of a flux tower. They found considerable variation in APAR due to cover, season, and sky conditions (diffuse vs. direct radiation) and discuss the implications of this variability for carbon flux.

Using a blimp-mounted spectrometer, Chen and Vierling (2006-this issue) explored spectral mixture analysis (SMA) for estimating cover fractions and highlighted the strengths and weaknesses of linear and non-linear SMA models. One conclusion from this study was that adding the NIR and SWIR spectral regions to the visible improved the results over those based on the visible region alone.

Fuentes et al. (2006-this issue) demonstrated how optical remote sensing can be combined with flux tower data to generate empirically calibrated "flux maps" illustrating the spatial and temporal variability in carbon and water vapor fluxes for flux tower sites. Gamon et al. (2006-this issue) and Claudio et al. (2006-this issue) illustrated the application of a tram system for automated, mobile sampling, and demonstrated how this robotic system can resolve the contribution of individual canopies and species to the overall fluxes and track successional change. Again, the implication of these studies is that we need far more attention to the impact of dynamic stand structure and cover type on fluxes. The explicit combination of optical sampling with flux measurements at these SpecNet sites provides a powerful means to achieve this objective. These 
results also highlight the utility of linked flux-optical sampling for extrapolating single-point flux measurements to larger regions.

\subsection{Exploring component fluxes}

Perhaps a more challenging issue than defining spatial patterns is the partitioning of the net fluxes into component fluxes, currently a key challenge within the flux sampling community. For example, ecosystem net carbon dioxide exchange (measured by eddy covariance) is comprised of gross carbon uptake by the ecosystem and respiratory release to the atmosphere, and eddy covariance alone cannot easily resolve these components (Moncreiff et al., 1996). Ecosystem
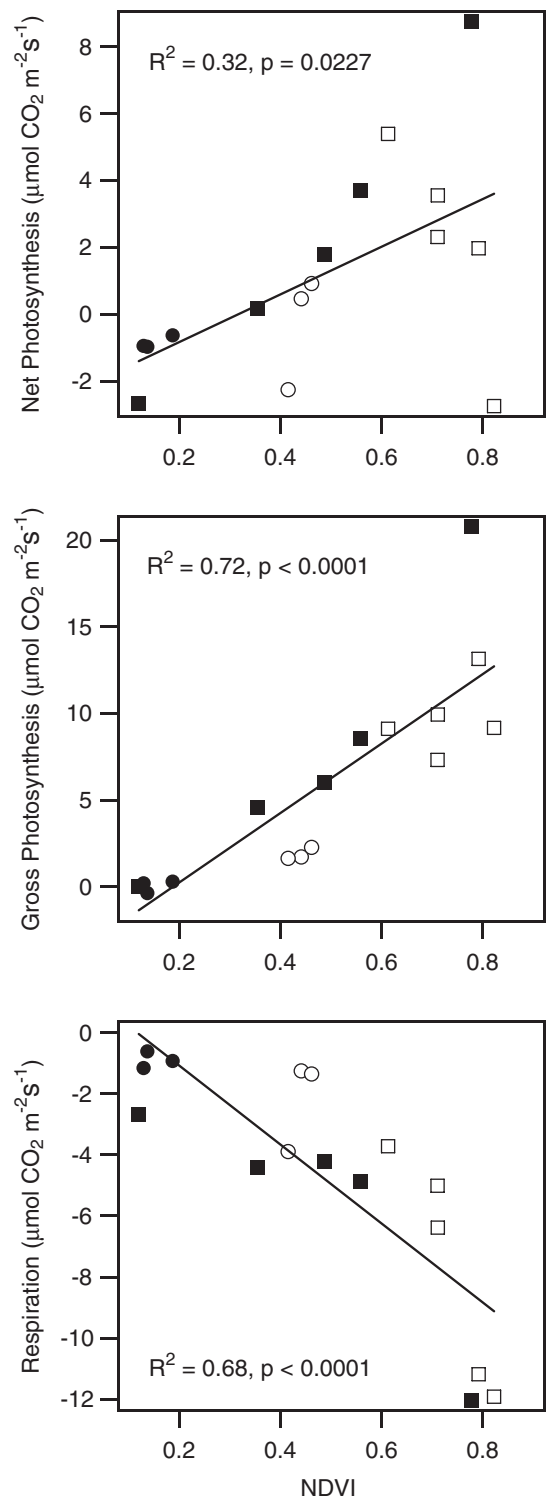

evapotranspiration is comprised of evaporation from surfaces, a passive process, and transpiration from vegetation, which is under physiological control. New findings indicate that living vegetation may be a key source of methane release to the atmosphere (Keppler et al., 2006). Presumably, methane release varies with cover type and physiological state, both of which are accessible with remote sensing, yet the links between optical signals, thermal signals, and methane release are essentially unexplored. These remaining challenges remind us that we have yet to fully understand the dynamic links between remote sensing and fundamental component fluxes of carbon and water.

Experimental studies at SpecNet sites are beginning to explore the link between common reflectance indices (NDVI and the water band index, WBI) and the component $\mathrm{CO}_{2}$ fluxes
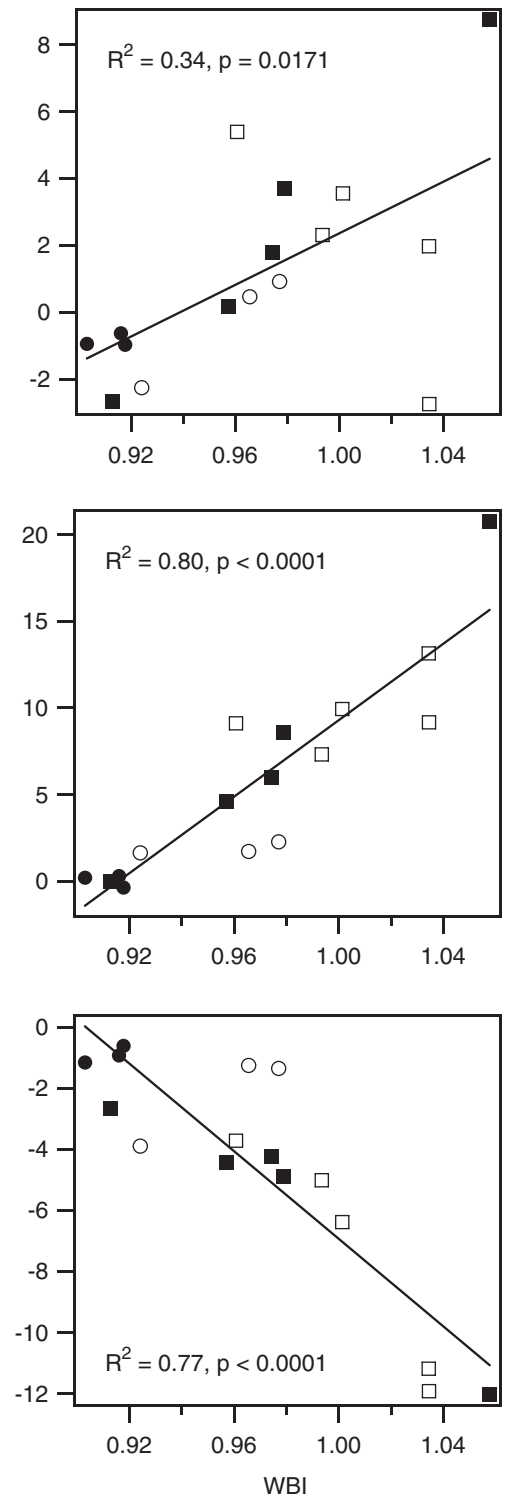

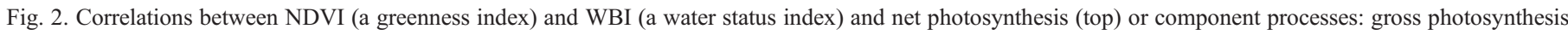

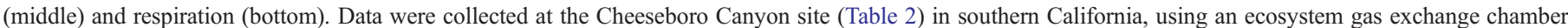

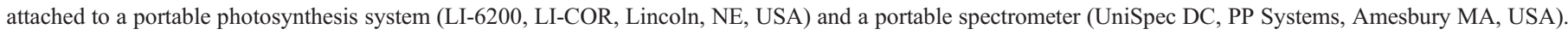

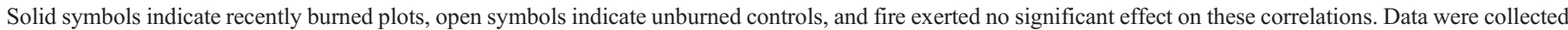

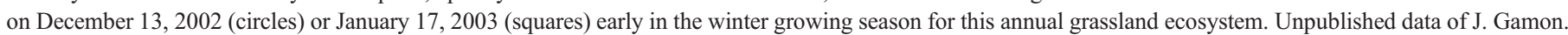


(Fig. 2). An initial conclusion is that both indices are often more strongly related to component fluxes (ecosystem respiration and gross photosynthesis) than to net ecosystem carbon flux (which is typically what flux towers measure). The similar correlations between NDVI and both carbon uptake and respiratory release reflect the tight coupling between the different components of overall carbon metabolism, both of which are strongly driven by water status in this grassland ecosystem. The finding of a significant correlation between optical indices and respiratory carbon release (Fig. 2) indicates that much of the carbon release is tightly coupled to recently fixed carbon, a finding consistent with other recent studies (Hogberg et al., 2001) and suggests the potential for remote sensing to have a more direct role in estimating the respiratory component of vegetation-atmosphere carbon exchange.

The surprisingly strong links between the water band index and the component fluxes (Fig. 2) remind us that, in many ecosystems, carbon flux is strongly influenced by water status, which is also remotely detectable with new hyperspectral methods. The results of Fuentes et al. (2006-this issue) provide a further demonstration of this linkage between water and carbon fluxes. These findings also remind us that inferring fluxes from remote sensing rests on correlations that can change in time and space, and that to understand these correlations, we need to better understand the "ecological rules" controlling them. One way to do this would be through ecosystem experiments that explore the effect of ecosystem perturbations on fluxes and optical properties sampled at different scales. Furthermore, we need to conduct more crosssite comparisons to see how these relationships vary across ecosystems.

\subsection{Satellite validation}

One SpecNet objective involves using field-based optical data concurrent with flux measurements to independently assess the accuracy of satellite data products. These products include reflectance indices (e.g. NDVI), derived biophysical properties (e.g. FPAR and LAI), and estimated fluxes (e.g. net carbon exchange, evapotranspiration, or their component fluxes). Hill et al. (2006-this issue) compared continuous field sampling to satellite overpasses, identifying several challenges to comparing multiple sensors at different scales. Cheng et al. (2006-this issue) directly compared reflectance indices and FPAR estimates from MODIS to those obtained from aircraft and automated field spectrometers and found that certain satellite products (e.g. NDVI and FPAR) tended to be systematically higher than those from aircraft or field spectrometers (which tended to agree well with each other). On the other hand, the satellite-derived Enhanced Vegetation Index (EVI), which corrects for soil background as well as atmospheric effects, agreed well with aircraft and fieldderived values.

These systematic biases apparent in certain satellite products have implications for global carbon cycle modeling, since many of the global models are based on these satellite products (e.g. Running et al., 2004). Careful cross platform and field sampling validation studies are rarely conducted and these findings of differences across instruments and sampling platforms, while not surprising, illustrate the importance of standardizing instruments, measurements and sampling approaches, a fundamental SpecNet goal.

This study suggests that many of our satellite products are indeed "works in progress" that need further refinement and validation if they are to produce defensible estimates of biospheric carbon fluxes. It also illustrates that existing satellite sensors, while often very well validated at a technical, engineering level, remain largely unvalidated at the level of their final products used for carbon flux and other global models. Yet, apart from a handful of validation studies (e.g. Cheng et al., 2006-this issue; Huemmrich et al., 2005; Rahman et al., 2004; Turner et al., 2003) the comparison of current satellite products against actual field data has received scant attention in the Earth system science literature, and probably reflects insufficient funding for a vigorous validation of satellite products (Lawler, 1997, 1999). Clearly, further validation is warranted, and SpecNet's ability to apply multi-scale optical sampling at flux tower sites provides a unique and timely approach to evaluating current and future satellite products.

\subsection{Ecoinformatics challenges}

An ultimate goal of SpecNet is to have data standardized and accessible in such a way that cross-ecosystem and cross-scale analyses can be readily conducted. These kinds of metaanalyses are essential if we are to produce properly validated products and integrative analyses from satellite coverage (Green et al., 2005). Integrating different data sources from different science communities, spanning many scales and multiple locations, raises serious challenges in the area of informatics. Thus, an essential requirement emerging from the early stages of SpecNet is the need for a systematic approach for the collection, storage, processing and retrieval of optical data. The large volumes of data readily attainable with spectrometers (particularly imaging spectrometers, hyperspectral spectrometers, and automated spectrometers), and the disparate nature of the data from different instruments, sampling resolutions, platforms, and error sources makes this a particularly difficult challenge. Attention to data format, and to the metadata that allow ready use and re-use of those data, is essential if we are to draw intelligent conclusions (Green et al., 2005).

Ideally, any informatics approach would readily integrate optical data, flux data, and other ecologically significant information (e.g. species composition and stand age and structure). Such databases do not yet exist because of the inherent complexity of integrating heterogeneous data sources collected for many different purposes by different organizations, yet several examples of nascent versions can be found. For example, the BOREAS project produced separate datasets of remote sensing, flux data, and ecological data, but the integration between these parts remains a challenge (Newcomer et al., 2001). Similarly, in collaboration with the National Center for Ecological Analysis and Synthesis (NCEAS), the SpecNet community is developing ecological databases that include spectral data, but flux data and remote sensing data (generally 
maintained by separate communities and agencies) are not yet integrated with these. Some recent efforts in ecoinformatics are exploring how rich metadata-driven approaches can provide loose data confederation, and assist with integrating disparate data sources without the need for a concerted modeling effort (Jones et al., 2001).

A key SpecNet goal remains the development of informatics approaches that allow the integration of these different datasets. Aside from the informatics challenges, for this integration to work effectively, data sharing policies will have to be examined, access to data will have to improve, and collaboration between flux and remote sensing communities needs to be enhanced. Many obstacles to full collaboration exist, partly arising from different approaches to data collection and distribution across disciplines. For example, much remote sensing data lie in the public domain, whereas flux tower data tend to be collected by individual investigators who may choose to restrict the use of data by other researchers for several years. Furthermore, within the USA, different agencies tend to fund flux tower and remote sensing research, with most of the flux funding coming from DOE, and much of the remote sensing funding coming from NASA, each with their own goals and data sharing requirements. An additional challenge to the informatics goal of SpecNet remains the fact that agencies generally fund science, not databases or informatics per se, leaving it unclear how the actual work of building interdisciplinary databases will be accomplished. While collaboration between communities is sometimes encouraged, and timely data sharing is sometimes an agency requirement (BOREAS provides one example), incentives for collaboration needed to accomplish the informatics goals could be significantly improved (Estrin et al., 2003).

\section{Conclusion}

The effective integration of optical and flux data remains a difficult yet essential challenge, and SpecNet provides a valuable foundation for this task. SpecNet is still in its infancy, and the geographical coverage is relatively limited (Table 1). To be fully effective in its goals of understanding biospheric fluxes across sites and scales, a far greater variety of ecosystems and geographic locations must be included, and strong incentives for improved interdisciplinary collaboration are needed. We invite the scientific community to join in this effort.

\section{Acknowledgements}

The SpecNet Working Group was made possible by a grant from the National Center for Ecological Analysis and Synthesis (NCEAS). Thanks to the many working group participants and SpecNet investigators, who provide continued inspiration for this effort. Thanks to the staff of the Santa Monica Mountains National Recreation Area (US Park Service) for access to the Cheeseboro Canyon site (Fig. 2). D. Kimura provided the artwork for Fig. 1. Completion of this manuscript was made possible with support from NSF CREST and Ecosystems grants to J.A.G.

\section{References}

Asner, G. P., Wessman, C. A., Schimel, D. S., \& Archer, S. (1998). Variability in leaf and litter optical properties: Implications for BRDF model inversions using AVHRR, MODIS and MISR. Remote Sensing of Environment, 63, 243-257.

Castro-Esau, K. L., Sanchez-Azofeifa, A., \& Rivard, B. (2006). Comparison of spectral indices obtained using multiple spectroradiometers. Remote Sensing of Environment, 103, 276-288 (this issue). doi:10.1016/j. rse.2005.01.019.

Chen, X., \& Vierling, L. (2006). Spectral mixture analyses of hyperspectral data acquired using a tethered balloon. Remote Sensing of Environment, 103, 338-350 (this issue). doi:10.1016/j.rse.2005.05.023.

Cheng, Y., Gamon, J. A., Fuentes, D. A., Mao, Z., Sims, D. A., Qui, H. -L., et al. (2006). A multi-scale analysis of dynamic optical signals in a Southern California chaparral ecosystem: A comparison of field, AVIRIS and MODIS data. Remote Sensing of Environment, 103, 369-378 (this issue). doi:10.1016/j.rse.2005.06.013.

Claudio, H. C., Cheng, Y., Fuentes, D. A., Gamon, J. A., Luo, H., \& Oechel, W. (2006). Monitoring drought effects on vegetation water content and fluxes in chaparral with the $970 \mathrm{~nm}$ water band index. Remote Sensing of Environment, 103, 304-311 (this issue). doi:10.1016/j.rse.2005.07.015.

Daughtry, C. S. T., Ranson, K. J., \& Biehl, L. L. (1989). A new technique to measure the spectral properties of conifer needles. Remote Sensing of Environment, 27, 81-91.

Dawson, T. P., Curran, P. J., \& Plummer, S. E. (1998). LIBERTY - Modeling the effects of leaf biochemical concentration on reflectance spectra. Remote Sensing of Environment, 65(1), 50-60.

Estrin, D., Michener, W., \& Bonito, G. (2003). Environmental cyberinfrastructure needs for distributed sensor networks: A report from a National Science Foundation Sponsored Workshop. 12-14 August. Scripps Institute of Oceanography.

Filella, I., Peñuelas, J., Llorens, L., \& Estiarte, M. (2004). Reflectance assessment of seasonal and annual changes in biomass and $\mathrm{CO}_{2}$ uptake of a Mediterranean shrubland submitted to experimental warming and drought. Remote Sensing of Environment, 90, 308-318.

Foley, S. E., Rivard, B., Sanchez-Azofeifa, A., \& Calvo-Alvarado, J. C. (2006). Foliar spectral properties following leaf clipping and implications for handling techniques. Remote Sensing of Environment, 103, 265-275 (this issue). doi:10.1016/j.rse.2005.06.014.

Fuentes, D. A., Gamon, J. A., Cheng, Y., Qui, H. -L., Mao, Z., Sims, D. A., et al. (2006). Mapping carbon and water vapor fluxes in a chaparral ecosystem using vegetation indices derived from AVIRIS. Remote Sensing of Environment, 103, 312-323 (this issue). doi:10.1016/j.rse.2005.10.028.

Gamon, J. A., Cheng, Y., Claudio, H. C., MacKinney, L., et al. (2006). A mobile tram system for systematic sampling of ecosystem optical properties. Remote Sensing of Environment, 103, 246-254 (this issue). doi:10.1016/j.rse.2005.04.006.

Gamon, J. A., Field, C. B., Goulden, M., Griffin, K., Hartley, A., Joel, G., et al. (1995). Relationships between NDVI, canopy structure, and photosynthetic activity in three Californian vegetation types. Ecological Applications, 5(1), $28-41$.

Gamon, J. A., Huemmrich, K. F., Peddle, D. R., Chen, J., Fuentes, D., Hall, F. G., et al. (2004). Remote sensing in BOREAS: Lessons learned. Remote Sensing of Environment, 89, 139-162.

Gamon, J. A., Peñuelas, J., \& Field, C. B. (1992). A narrow-waveband spectral index that tracks diurnal changes in photosynthetic efficiency. Remote Sensing of Environment, 41, 35-44.

Gamon, J. A., \& Surfus, J. S. (1999). Assessing leaf pigment content and activity with a reflectometer. New Phytologist, 143, 105-117.

Goel, N. S. (1988). Models of vegetation canopy reflectance and their use in estimation of biophysical parameters from reflectance data. Remote Sensing Reviews, 4, 1-212.

Goulden, M. L., Daube, B. C., Fan, S. M., Sutton, D. J., Bazzaz, A., Munger, J. W., et al. (1997). Physiological responses of a black spruce forest to weather. Journal of Geophysical Research, 102(D24), 28987-28996.

Green, J. L., Hastings, A., Arzberger, P., Ayala, F. J., Cottingham, K. L., Cuddington, K., et al. (2005). Complexity in ecology and conservation: 
Mathematical, statistical, and computational challenges. Bioscience, 55(6), 501-510.

Hill, M. J., Held, A., Leuning, R., Coops, N., Hughes, D., \& Cleugh, H. (2006). MODIS spectral signals at a flux tower site: Relationships with high resolution data, and $\mathrm{CO}_{2}$ flux and light use efficiency measurements. Remote Sensing of Environment, 103, 351-368 (this issue). doi:10.1016/j.rse.2005.06.015.

Hogberg, P., Nordgren, A., Buchmann, N., Taylor, A. F. S., Ekblad, A., \& Hogberg, M. N. (2001). Large-scale forest girdling shows that current photosynthesis drives soil respiration. Nature, 411, 789-792.

Huemmrich, K. F., Privette, J. L., Mukelabai, M., Myneni, R. B., \& Knyazikhin, Y. (2005). Time-series validation of MODIS land biophysical products in a Kalahari woodland, Africa. International Journal of Remote Sensing, 26 (19), 4381-4398.

Jones, M. B., Berkley, C., Bojilova, J., \& Schildhauer, M. (2001). Managing scientific metadata. IEEE Internet Computing, 5(5), 59-68.

Keppler, F., Hamilton, J. T. G., Bra, M., \& Röckmann, T. (2006). Methane emissions from terrestrial plants under aerobic conditions. Nature, 439, 187-191.

Lawler, A. (1997). Mission to planet Earth: NASA boosts earth science grants. Science, 277, 1198

Lawler, A. (1999). Earth science: Terra launch spotlights NASA observing system. Science, 286, 2064-2065.

Leuning, R., Hughes, D., Daniel, P., Coops, N. C., \& Newnham, G. (2006). A multi-angle spectrometer for automatic measurement of plant canopy reflectance spectra. Remote Sensing of Environment, 103, 236-245 (this issue). doi:10.1016/j.rse.2005.06.016.

Middleton, E. M. (1992). Quantifying reflectance anisotropy of photosynthetically active radiation in grasslands. Journal of Geophysical Research D, Atmospheres, 97, 18935-18946.

Moncreiff, J. B., Malhi, Y., \& Leuning, R. (1996). The propagation of errors in long-term measurements of land-atmosphere fluxes of carbon and water. Global Change Biology, 2, 231-240.

Newcomer, J. A., Huemmrich, K. F., Landis, D., Nickeson, J., Conrad, S. Knapp, D., et al. (2001). Managing and supporting large integrated and interdisciplinary field studies: The BOREAS example. Journal of Geophysical Research, 106(D24), 33,517-33,528.

Nichol, C. J., Huemmrich, K. F., Black, T. A., Jarvis, P. J., Walthall, C. L., Grace, J., et al. (2000). Remote sensing of photosynthetic light-use efficiency of boreal forest. Agricultural and Forest Meteorology, 101, 131-142.

Oliphant, A. J., Grimmond, S. B., Schmid, H. -P., \& Wayson, C. A. (2006). Local-scale heterogeneity of photosynthetically active radiation (PAR), absorbed PAR and net radiation as a function of topography, sky conditions and leaf area index. Remote Sensing of Environment, 103, 324-337 (this issue). doi:10.1016/j.rse.2005.09.021.

Rahman, A. F., Cordova, V. D., Gamon, J. A., Schmid, H. P., \& Sims, D. A. (2004). Potential of MODIS ocean bands for estimating $\mathrm{CO}_{2}$ flux from terrestrial vegetation: A novel approach. Geophysical Research Letters, 31, L10503. doi:10.1029/2004GL019778
Rahman, A. F., Gamon, J. A., Fuentes, D. A., Roberts, D. A., \& Prentiss, D. (2001). Modeling spatially distributed ecosystem flux of boreal forests using hyperspectral indices from AVIRIS imagery. Journal of Geophysical Research, 106(D24), 33,579-33,591.

Raupach, M. R., Rayner, P. J., Barrett, D. J., DeFries, R., Heimann, M., Ojima, D. S., et al. (2005). Model-data synthesis in terrestrial carbon observation: Methods, data requirements and data uncertainty specifications. Global Change Biology, 11, 378-397.

Running, S. W., Baldocchi, D. D., Turner, D. P., Gower, S. T., Bakwin, P. S., \& Hibbard, K. A. (1999). A global terrestrial monitoring network integrating tower fluxes, flask sampling, ecosystem modeling, and EOS satellite data. Remote Sensing of Environment, 70, 108-127.

Running, S. W., Nemani, R. R., Heinsch, F. A., Zhao, M., Reeves, M., \& Hashimoto, H. (2004). A continuous satellite-derived measure of global terrestrial primary production. Bioscience, 54, 547-560.

Sellers, P. J., Bounoua, L., Collatz, G. J., Randall, D. A., Dazlich, D. A., Los, S. O., et al. (1996). Comparison of radiative and physiological effects of doubled atmospheric $\mathrm{CO}_{2}$ on climate. Science, 271, 1402-1406.

Sims, D. A., Luo, H., Hastings, S., Oechel, W. C., Rahman, A. F., \& Gamon, J. A. (2006). Parallel adjustments in vegetation greenness and ecosystem $\mathrm{CO}_{2}$ exchange in response to drought in a Southern California chaparral ecosystem. Remote Sensing of Environment, 103, 289-303 (this issue). doi:10.1016/j.rse.2005.01.020.

Sims, D. A., Rahman, A. F., Cordova, V. D., Baldocchi, D. D., Flanagan, L. B., \& Goldstein, A. H. (2005). Midday values of gross $\mathrm{CO}_{2}$ flux and light use efficiency during satellite overpasses can be used to directly estimate eightday mean flux. Agricultural and Forest Meteorology, 131, 1-12.

Stylinski, C. D., Gamon, J. A., \& Oechel, W. C. (2002). Seasonal patterns of reflectance indices, carotenoid pigments and photosynthesis of evergreen chaparral species. Oecologia, 131, 366-374.

Tans, P. P., Fung, I. Y., \& Takahashi, T. (1990). Observational constraints on the global atmospheric $\mathrm{CO}_{2}$ budget. Science, 247, 1431-1438.

Turner, D. P., Ritts, W. D., Cohen, W. B., Gower, S. T., Zhao, M., Running, S. W., et al. (2003). Scaling gross primary production (GPP) over boreal and deciduous forest landscapes in support of MODIS GPP product validation. Remote Sensing of Environment, 88, 256-270.

Turner, D. P., Ritts, W., Cohen, W. B., Maeirsperger, T., Gower, S. T., Kirschbaum, A., et al. (2005). Site-level evaluation of satellite-based global GPP and NPP monitoring. Global Change Biology, 11, 666-684.

Verhoef, W. (1984). Light scattering by leaf layers with application to canopy reflectance modeling: The SAIL model. Remote Sensing of Environment, 16, $125-141$.

Vierling, L., Fersdahl, M., Chen, X., \& Zimmerman, P. (2006). The Short Wave Aerostat-Mounted Imager (SWAMI): A novel platform for acquiring remotely sensed data from a tethered balloon. Remote Sensing of Environment, 103, 255-264 (this issue). doi:10.1016/j.rse.2005.01.021. 